\title{
RAZGLEDI
}

\section{RAZVOJ PODEŽELJA NA OBMOČJU PREDVIDENEGA KRAJINSKEGA PARKA DRAGONJA: MNENJE AKTIVNIH PREBIVALCEV}

\author{
AVTORICE \\ Janina Torkar \\ Mirna pot 2a, SI - 6310 Izola, Slovenija \\ janina.torkar@gmail.com

\section{dr. Valentina Brečko Grubar} \\ Univerza na Primorskem, Fakulteta za humanistične študije, Titov trg 5, SI - 6000 Koper, Slovenija \\ valentina.brecko.grubar@fhs.upr.si
}

\section{dr. Romina Rodela}

Univerza Södertörn, Fakulteta za naravoslovje, tehnologijo in okoljske študije, SE - 14189 Huddinge, Švedska in Univerza $v$ Wageningenu, Oddelek za geoinformacijsko znanost in daljinsko zaznavanje, Nizozemska rominarodela@hotmail.com

DOI: $10.3986 / G V 89103$

UDK: 711.3:502.131.1(497.472)

COBISS: 1.01

\section{IZVLEČEK}

Razvoj podeželja na območju predvidenega Krajinskega parka Dragonja: mnenje aktivnih prebivalcev $V$ članku predstavljamo rezultate raziskave, izvedene $v$ podeželskih naseljih na območju predvidenega Krajinskega parka Dragonja. Z analizo dokumentov, opazovanjem na delavnici in intervjuji desetih aktivnih prebivalcev smo pridobili podatke o obveščenosti in zanimanju za aktivno vključevanje $v$ razvoj, o vrednotenju okolja in njegovih virov ter o željah in pričakovanjih glede sprememb ter kakovosti življenja. Ugotovili smo, da so vprašani dobro seznanjeni z razvojnimi programi in projekti, $k i$ so se ali se še izvajajo, da se zavedajo pomena varovanja naravne in kulturne dediščine $v$ trajnostnem razvoju ter da želijo aktivno sodelovati v prihodnje. S pomočjo sogovornikov, opazovanja in analize dokumentov pa smo spoznali tudi manj obetavno plat razvoja. Ugotovili smo, da je bila dinamika participacije prebivalcev v preteklosti šibka, da so sodelujoči $v$ manjšini in so spremembe odvisne od prizadevanj posameznikov. Prebivalci vodmaknjenih naseljih na območju predvidenega Krajinskega parka Dragonja so maloštevilni in večinoma starejši, mlajši so sprijaznjeni z nemočjo. V prihodnje bo za aktivnejše sodelovanje v razvoju potrebnega več ozaveščanja, motiviranja ter izobraževanja, pomembno vlogo pa bodo imeli tudi priseljeni mlajši prebivalci.

\section{KLJUČNE BESEDE}

razvoj podeželja, vključevanje lokalnega prebivalstva, aktiviranje prebivalcev, trajnostni razvoj, krajinski park, porečje Dragonje, slovenska Istra 


\begin{abstract}
Rural development in the prospective Dragonja Landscape Park: a viewpoint from active inhabitants The article presents the results of a research done in rural settlements located within the area of the prospective Dragonja Landscape Park. We analysed documents of local communities, undertook observation of a workshop, and interviewed ten local inhabitants in order to obtain information about local inhabitants' awareness and their interest in being involved in rural development, and about their valuing of the environment and natural resources, and to gain insight into their expectations in the matters of quality of life. We have established that our respondents are entirely familiar with the past and current development programs and projects, that they are well aware of the importance the protection of natural and cultural heritage has for sustainable development, and that they want to participate actively in the future. With the help of our respondents, observation in the workshop, and analysis of the documents also the less promising aspects of development have been revealed. We found out that local participation was weak in the past, that those who were active are in the minority, and that changes depend on the collective efforts of individuals. Those living in the remote villages located in the area of the prospective Dragonja Landscape Park are few and mostly of advanced age. It seems that the younger ones have resigned themselves to being powerless, and therefore it is urgent, in order to foster their participation in local development, to increase their awareness and motivation and extend their education. We also can expect that the incoming young people will have an important role to play.
\end{abstract}

\title{
KEY WORDS
}

rural development, public participation, capacity building, sustainable development, landscape park, Dragonja River basin, Slovenian Istria

Uredništvo je prispevek prejelo 30. marca 2016. 


\section{Uvod}

Prepletanje tradicionalne rabe naravnih virov okolja in načina življenja domačinov na podeželju slovenske Istre je skozi stoletja oblikovalo kulturno pokrajino, kot jo poznamo danes. Lokalni naravni viri so človeku zagotavljali osnovne surovine za preživetje. Zlasti rodovitna prst in pitna voda sta, skupaj z blagim obsredozemskim podnebjem, omogočili zgodnjo in gosto naseljenost tega območja. Še v obdobju med svetovnima vojnama je bilo zaledje slovenske Istre agrarno prenaseljeno in prebivalci so se težko preživljali, kar je bil tudi razlog za izseljevanje. To je bilo še posebej intenzivno po drugi svetovni vojni, ko so naselja zapuščali predvsem mladi, ostareli prebivalci pa so postopoma opuščali kmetovanje in niso obnavljali svojih domov. Kulturna pokrajina se je do danes marsikje že spremenila v gozdnato in kulturna dediščina propada, pozitivna posledica praznjenja naselij pa je ohranjeno naravno okolje in $\mathrm{v}$ precejšnji meri ohranjena tradicionalna arhitektura. In prav zaradi ohranjenosti naravnega okolja in dodane vrednosti, ki jo ta prinaša h kakovosti bivanja, se je $\mathrm{v}$ zadnjih letih uveljavilo mnenje, da je to območje primerno predvsem za razvoj tistih gospodarskih dejavnosti, ki naravo obremenjujejo v manjši meri, predvsem za turizem in rekreacijo. Precej starejša pa je pobuda Zavoda za varstvo narave Piran o varovanju narave oziroma zavarovanju porečja Dragonje, ki je stara že skoraj tri desetletja. V zadnjih letih so se izoblikovale tudi pobude za trajnostni razvoj podeželja slovenske Istre. Zasnovali in uresničujejo jih ljudje, ki na tem območju živijo in delujejo. Del teh pobud se usmerja v trajnostne prakse v kmetijstvu, podjetništvu, turizmu, hkrati pa podpirajo varovanje okolja in narave ter pobude za vzpostavitev naravnega parka v porečju Dragonje. Opaziti je vse večje uveljavljanje interesa za pozitivne spremembe in $\mathrm{v}$ ta namen so se prebivalci začeli povezovati. Novodobne pobude, kot sta na primer »Mreža za preporod Istre« in Podeželski parlament (Mreža ... 2015), so pomembni koraki, čeprav so večinoma pritegnili aktivne posameznike, društva in organizacije, ki se že vrsto let trudijo z oživljanjem podeželja. Tovrstne pobude pa same po sebi še niso zadostne za uresničevanje dolgoročnih ciljev trajnostnega razvoja v slovenski Istri, ki terja sodelovanje širše skupnosti. Z namenom, da bi bolje spoznali možnosti za razvoj na območju predvidenega Krajinskega parka (v nadaljevanju KP) Dragonja, smo v času od aprila do junija 2015 opravili raziskavo in v prispevku strnili ključne ugotovitve.

\section{Možnosti za sodelovanje lokalnega prebivalstva v trajnostnem razvoju}

V različnih virih je trajnostni razvoj opredeljen kot skupni cilj, ki se uresničuje prek sodelovanja med institucijami in ostalimi družbenimi akterji, kot so nevladne organizacije, lokalne skupnosti, gospodarski subjekti in drugi (Pretty in Smith 2004; Plummer in Fitz Gibbon 2006; Brondizio, Ostrom in Young 2009; Boström, Rabe in Rodela 2015; Rodela in sodelavci 2017). V tej povezavi se v ospredje postavljajo lokalni prebivalci, torej tisti, ki v določenem okolju živijo in ga tudi najbolje poznajo (Arnstein 1969; Ostrom 1990; 2000). Že Arnsteinova (1969) je izpostavila potrebo po vključevanju in sodelovanju lokalne skupnosti in menila, da mora biti skupnost obveščena v zgodnjih fazah načrtovanja posegov v prostor ali sprejemanja odločitev. Treba je zagotoviti možnosti, da prebivalci aktivno prispevajo k oblikovanju usmeritev in pri ciljih razvoja svojega življenjskega prostora. Trdila je, da se učinkovita udeležba lokalnega prebivalstva kaže prav v moči usmerjanja in odločanja (Arnstein 1969). Njeno delo je imelo pomemben vpliv na obravnavo problematike varovanja okolja, $\mathrm{v}$ okviru katere se je v 70. letih uveljavil pristop »od spodaj navzgor «, ki je sicer odmeval širše in je močno zaznamoval tudi teorijo razvoja podeželja v Evropi (High in Nemes 2007). Tudi Potočnik Slavičeva (2008; 2009; 2010) izpostavlja, da ima pri razvoju podeželja, poleg okoljskega in ekonomskega kapitala, največjo težo prav socialni kapital, saj primeri dobrih praks kažejo, da je ključ do uspešnega razvoja lokalnega okolja prav v dobrem medsebojnem sodelovanju lokalnega prebivalstva, nevladnih organizacij, lokalne skupnosti, naravovarstvenih organizacij in države. Toda razpoložljivost socialnega kapitala v neki skupnosti je del širše razvojne pobude in je odvisna od specifičnih okoliščin, prisotnih na nekem območju, kar je tudi dokazala v študiji 
vloge lokalnih društev v treh slovenskih podeželskih območjih. Iz literature poznamo različne ravni participacije, od enostavnega posredovanja informacij, do prenosa moči in odgovornosti (Arnstein 1969; Pretty 2003). Razumevanje sodelovanja kot orodja za doseganje zastavljenih ciljev nam olajša izbiro ustreznih ravni, kjer se promovira in pospešuje sodelovanje, ter posledično poveča možnosti želenega izida, hkrati pa nam zmanjša stroške izvršitve (Mannigel 2008). Socialni kapital je ključen tudi za krepitev pripadnosti in identitete, za razvoj demokratičnih odnosov in večjega zaupanja v institucije (Pretty in Smith 2004; Milestad in sodelavci 2010; Guštin in Potočnik Slavič 2015). Socialni kapital ima pomembno vlogo tudi pri upravljanju zavarovanih območij. Predhodne študije so dokazale, da sodelovanje in vključevanje lokalnega prebivalstva pripomore $\mathrm{k}$ bolj uspešnemu izvajanju naravovarstvenih ciljev (Rodela 2006). Viri, ki obravnavajo razvoj podeželja, pa izpostavljajo socialni kapital kot ključni element in prvi pogoj za aktiviranje lokalnih razvojnih potencialov (High in Nemes 2007; Potočnik Slavič 2009).

V smeri lokalnega odločanja se je leta 1991, po pobudi Evropske unije, začel oblikovati pristop LEADER - akronim za francosko poimenovano Liaison Entre Actionsde Développement del'Économie Rurale (The LEADER ... 2006). LEADER uveljavlja pristop »od spodaj navzgor « in je postavil ideje o sodelovanju skupnosti tudi v prakso (Pretty in Smith 2004; High in Nemes 2007). V Sloveniji se LEADER uspešno izvaja od leta 2007 v okviru Programa razvoja podeželja (Potočnik Slavič 2008; 2010; Podreka and Rodela 2013). Več kot desetletje pred tem, leta 1993, je Ministrstvo za kmetijstvo, gozdarstvo in prehrano (MKGP) pristopilo k izvajanju Celostnega razvoja podeželja in obnove vasi (CRPOV). To je bil prvi poskus celostnega reševanja podeželske problematike, ki je spodbujal k iskanju ravnovesja med kmetijsko-proizvodnimi in naravovarstvenimi cilji ter izboljšanjem kakovosti bivanja na podeželju (Hazler in sodelavci 1999). CRPOV se je na začetku usmeril na izbrana območja in o njegovi izvedbi so med drugimi poročali Pelc (2000) ter Kokolj-Prosekova in Golobičeva (2002). V fazi priprav ob vstopu v Evropsko unijo in z namenom, da bi CRPOV uskladili s cilji razvoja podeželja EU, je MKGP pripravilo Razvojni program podeželja (RPP). Ta je služil kot podlaga za izvajanje ukrepov razvoja podeželja in med drugim vključuje tudi LEADER, ki spodbuja sodelovanje, mreženje in izmenjavo izkušenj prek javno-zasebnih partnerstev. V javno-zasebna partnerstva se lahko vključujejo lokalni akterji, gospodarski subjekti, različna društva, javni zavodi, civilne iniciative (Moseley 2003; Shucksmith 2010), ki se združujejo v tako imenovane lokalne akcijske skupine (LAS) z možnostjo prijavljanja na projekte, za izvedbo le-teh pa prejmejo sredstva. Namen tega je spodbujanje iniciativ za razvoj podeželja iz lokalnega okolja in ustvarjanje delovnih mest. Teme tovrstnih projektov so različne, od varstva okolja in ohranjanja narave do vključevanja mladih, žensk ter drugih ranljivih skupin. Namen teh pa je izboljšanje kakovosti življenja za vse. Uspešnost izvedbe razvojnih projektov je v celoti odvisna od aktivnosti lokalnega prebivalstva, od prepoznanih potencialov v lokalnem okolju, razvojnih prioritet na podeželju in kakovostne priprave projektnega gradiva (Evropski ... 2013). LEADER, ki so ga ob posodobitvi preimenovali v Community-Led Local Development (CLLD), se izvaja v okviru strukturnih skladov Evropske unije, skladno z Uredbo o izvajanju lokalnega razvoja skupnosti. Za programsko obdobje 2014-2020 je za izvedbo CLLD v Sloveniji namenjenih 95.782.281,19 evrov (Evropski ... 2013). Ocene uspešnosti in zadovoljstvo z izvajanjem programa LEADER se razlikujejo med državami članicami EU, analitiki pa poudarjajo zaplete in težave predvsem $\mathrm{v}$ državah, kjer se podeželje že več let sooča s praznjenjem naselij in staranjem prebivalstva (Barke in Newton 1997; Kovách 2000).

\section{Metode dela}

V raziskavi, ki je potekala od aprila do junija 2015, in se je osredotočala na podeželje slovenske Istre v mejah predvidenega KS Dragonja, je bila uporabljena triangulacija metod. Izvedli smo analizo dokumentov, opazovanje in intervjuje (preglednica 1). Triangulacija metod je pristop, kjer uporabimo več metod zbiranja podatkov z namenom kombiniranja, povezovanja in preverjanja ugotovitev o preučevanih pojavih 
(Denzin in Lincoln 2000). Triangulacija omogoča, da si ustvarimo popolnejšo podobo o preučevanem pojavu, ne pa tudi objektivnejše, kot poudarja Vogrinc (2008). Naša raziskava je bila izvedena v več korakih. Najprej smo pregledali spletne strani in dostopne dokumente krajevnih skupnosti (na primer Gradin, Gračišče, Šmarje), društev (na primer Društvo za trajnostni razvoj Istre, Društvo za trajnostni razvoj vasi Labor, Turistično kulturno društvo Pomjan) in zavodov (Zavod Eko-Humanitatis, Zavod Interso, Zavod za socialno podjetje Istraterra, Zavod Terra viva, Zavod Trajnostni park Istra), ki so povezani v Mrežo za preporod Istre. Preučili smo oba Regionalna razvojna programa za Južno Primorsko regijo, tako iz preteklega obdobja 2007-2013, kot tekočega za obdobje 2014-2020. S pomočjo analize dokumentov smo spoznali aktivnosti in njihove lokalne pobudnike, prepoznali nosilce interesov in vlogo le-teh pri razvoju. Na podlagi pridobljenega medmrežnega gradiva Mestne občine Koper (MOK) smo dobili vpogled $\mathrm{v}$ vlaganja in finančne spodbude za razvoj. Pridobljene podatke smo uporabili pri oblikovanju vprašanj za intervjuje ter pri pripravi na opazovanje izbranega dogodka.

Preglednica 1: Triangulacija uporabljenih metod.

\begin{tabular}{|c|c|c|c|}
\hline & pregled dokumentov & opazovanje & $\begin{array}{l}\text { pridobljena sredstva preko } \\
\text { razvojnih skladov }\end{array}$ \\
\hline namen & $\begin{array}{l}\text { pridobivanje in } \\
\text { preverjanje podatkov }\end{array}$ & $\begin{array}{l}\text { pridobivanje in } \\
\text { preverjanje podatkov }\end{array}$ & $\begin{array}{l}\text { pridobivanje in } \\
\text { preverjanje podatkov }\end{array}$ \\
\hline podatki & kvalitativni in kvantitativni & kvalitativni & kvalitativni \\
\hline $\begin{array}{l}\text { metoda } \\
\text { vzorčenja }\end{array}$ & namenska & namenska & namenska \\
\hline vzorec & $\begin{array}{l}18 \text { dokumentov } \\
12 \text { spletnih strani }\end{array}$ & $\begin{array}{l}\text { delavnica »soustvarjamo } \\
\text { trajnostni razvoj podeželja } \\
\text { Istre« }\end{array}$ & $\begin{array}{l}\text { deset intervjuvancev } \\
\text { (domačini) }\end{array}$ \\
\hline $\begin{array}{l}\text { kako smo } \\
\text { pridobili } \\
\text { podatke }\end{array}$ & $\begin{array}{l}\text { pregled spletnih strani } \\
\text { krajevnih skupnosti, lokalnih } \\
\text { zavodov, nevladnih organizacij, } \\
\text { s pregledom glasil krajevnih } \\
\text { skupnosti in internega } \\
\text { gradiva MOK }\end{array}$ & $\begin{array}{l}\text { opazovanje enkratnega } \\
\text { dogodka }\end{array}$ & $\begin{array}{l}\text { polstrukturirani intervjuji } \\
\text { z izbranimi sogovorniki }\end{array}$ \\
\hline $\begin{array}{l}\text { kako smo } \\
\text { uporabili } \\
\text { podatke/cilj }\end{array}$ & $\begin{array}{l}\text { Pregled dogodkov in investicij } \\
\text { smo uporabili pri razumevanju } \\
\text { razvojnih prioritet in dinamik } \\
\text { na območju ter podatke } \\
\text { o sodelujočih za navezavo } \\
\text { stikov s sogovorniki. }\end{array}$ & $\begin{array}{l}\text { Iz odzivov na dogodku smo } \\
\text { ugotovili, kdo so udeleženci, } \\
\text { kaj jih je motiviralo za } \\
\text { udeležbo in kako si želijo } \\
\text { sodelovati v razvoju. }\end{array}$ & $\begin{array}{l}\text { Besedne opise, pripovedi } \\
\text { in mnenja smo uporabili } \\
\text { za razumevanje pojava. }\end{array}$ \\
\hline časovni okvir & marec-oktober 2015 & september 2015 & april-junij 2015 \\
\hline
\end{tabular}

Prva avtorica se je kot opazovalka udeležila delavnice »Soustvarjamo trajnostni razvoj podeželja Istre«, ki jo je organiziral Zavod Eko-Humanitatis. Delavnice se je udeležilo okoli 85 slušateljev. Intervjuji so bili opravljeni z osebami, ki aktivno sodelujejo pri družbenih dejavnostih, v lokalnih organizacijah in/ali so zaposleni v kraju bivanja na območju raziskave. Imena intervjuvancev smo dobili s pomočjo analize dokumentov in udeležbe na delavnici ter z njimi vzpostavili stik. Želeli smo priti v stik s sogovorniki, ki so v različnih vlogah vpeti v dogajanje v lokalnem okolju. Polstrukturirani intervju je temeljil na devetih vprašanjih $\mathrm{z}$ več podvprašanji. Prvi sklop se je nanašal na poznavanje razvojnih spodbud 
in aktivnosti, na vpetost intervjuvancev v razvoj njihovega kraja oziroma širšega območja istrskega podeželja. V nadaljevanju so nas zanimale njihove želje po spremembah in pripravljenost za sodelovanje pri aktivnostih. Drugi sklop pa se je nanašal na vrednotenje okolja in varovanje narave. Pridobljeni odgovori so bili analizirani kvalitativno.

Naša študija je bila oblikovana kot kvalitativno-eksplorativna, saj je bil glavni namen pridobiti vpogled v izbrano temo. Triangulacijo metod smo uporabili z namenom pridobivanja in preverjanja podatkov, ne pa tudi kot kriterij presojanja kakovosti spoznanj kvalitativnega raziskovanja (Vogrinc 2008). Rezultati intervjujev, skupaj $\mathrm{z}$ rezultati analize dokumentov in opazovanja na delavnici, so sintezno predstavljeni v nadaljevanju. $Z$ namenom, da bi jih umestili v prostor, najprej predstavljamo območje, kjer je potekala raziskava, saj so prav obseg in dostopnost okoljskih virov ter družbeno-demografska struktura tisti, ki omogočajo poglobljeno razumevanje stanja.

\section{Geografski oris območja predvidenega Krajinskega parka Dragonja}

Območje predvidenega KP Dragonja obsega jugovzhodni del slovenske Istre, ki večinoma pripada Mestni občini Koper, z manjšim delom pa tudi Občini Piran. Obsega podeželje s številnimi majhnimi naselji in ohranjenim naravnim okoljem. Zlasti del, ki pripada Krajevni skupnosti Gradin, je prometno odmaknjen, redko poseljen in se še vedno sooča $\mathrm{z}$ zmanjševanjem števila prebivalcev. V podobnem položaju so tudi nekatera druga naselja znotraj predvidenega KP Dragonja, ki se nahajajo v sosednjih krajevnih skupnostih Šmarje, Marezige in Gračišče. Gričevnato flišno pokrajino s prevladujočo nadmorsko višino okoli $400 \mathrm{~m}$ členijo grape in ozke doline pritokov Dragonje in Bračane. Zadnja je del porečja Mirne, sicer pa večina območja pripada porečju Dragonje, ki je dominantni pokrajinotvorni element. Med dolinami s strmimi pobočji, zelo izpostavljenimi erozijskim procesom (Zorn 2008), se dvigajo planotasti hrbti in uravnave, ki so bili najbolj primeren prostor za gradnjo naselij ter kmetovanje. $Z$ gradnjo kulturnih teras so pridelavi hrane lahko namenili še strma prisojna pobočja, osojna pa so bila tudi v preteklosti gozdnata. Zaradi opuščanja kmetijstva gozd pokriva že več kot polovico površja in tudi velik del kulturnih teras. Ozka dna dolin s hudourniškimi vodnimi tokovi in izviri ob vznožju pobočij so bila nekoč pomembna za oskrbo z vodo, danes pa so to skriti kotički narave s flišnimi stenami, slapovi, tolmuni, prodišči in raznolikim življenjem, ki privlačijo obiskovalce. Ohranjeno okolje s številnimi naravnimi vrednotami in kulturna dediščina sta spodbudila želje in načrte za zavarovanje. Prve pobude za ustanovitev parka segajo že v 90. leta prejšnjega stoletja in še vedno čakajo na uresničitev.

Predvideno območje KP Dragonja (slika 1) naj bi obsegalo $116,5 \mathrm{~km}^{2}$ (Trampuš 2009). V številnih naseljih znotraj območja živi zgolj nekaj deset prebivalcev (na primer v Mučunigih, Abitantih, Belvedurju, Topolovcu, Laborju, Tuljakih, Zabavljah), veliko domov je praznih. Takšno stanje je posledica odseljevanja, ki je bilo prisotno že po prvi, zlasti pa po drugi svetovni vojni. Delovna mesta v obalnih naseljih so pritegnila mlado delovno silo, na domovih pa so ostali starejši, ki niso zmogli težavnega, v veliki meri ročnega obdelovanja. V naseljih znotraj meja predvidenega KP Dragonja je leta 2013 v 1196 gospodinjstvih živelo 3192 prebivalcev, v naseljih na njegovem obrobju pa v 1239 gospodinjstvih še 4339 prebivalcev (Torkar 2015). V slovenski Istri močno prisotna suburbanizacija, ki je značilna za podeželje bližje obali in obalnim mestom, območja predvidenega KP Dragonja ni dosegla. Demografski podatki za veliko naselij še vedno kažejo zmanjševanje števila prebivalcev in za večino neugodno starostno sestavo. Delež starega prebivalstva je velik in prav tako je zelo visok indeks staranja (Jerman 2011), ki je leta 2015 v več naseljih presegal 180, povprečna starost pa je 48 let (Krušec 2016). Negativni demografski trendi se postopoma umirjajo $\mathrm{v}$ dostopnejših naseljih bliže obali, ki postajajo privlačna za mlade družine (Kladnik, Pipan in Gašperič 2014). Boljše demografsko stanje je tudi v naseljih, ki so prevzela vlogo lokalnih središč ali so postala centralna naselja nižjih stopenj kot na primer Gračišče, Sveti Anton,

Slika 1: Območje predvidenega KP Dragonja. 


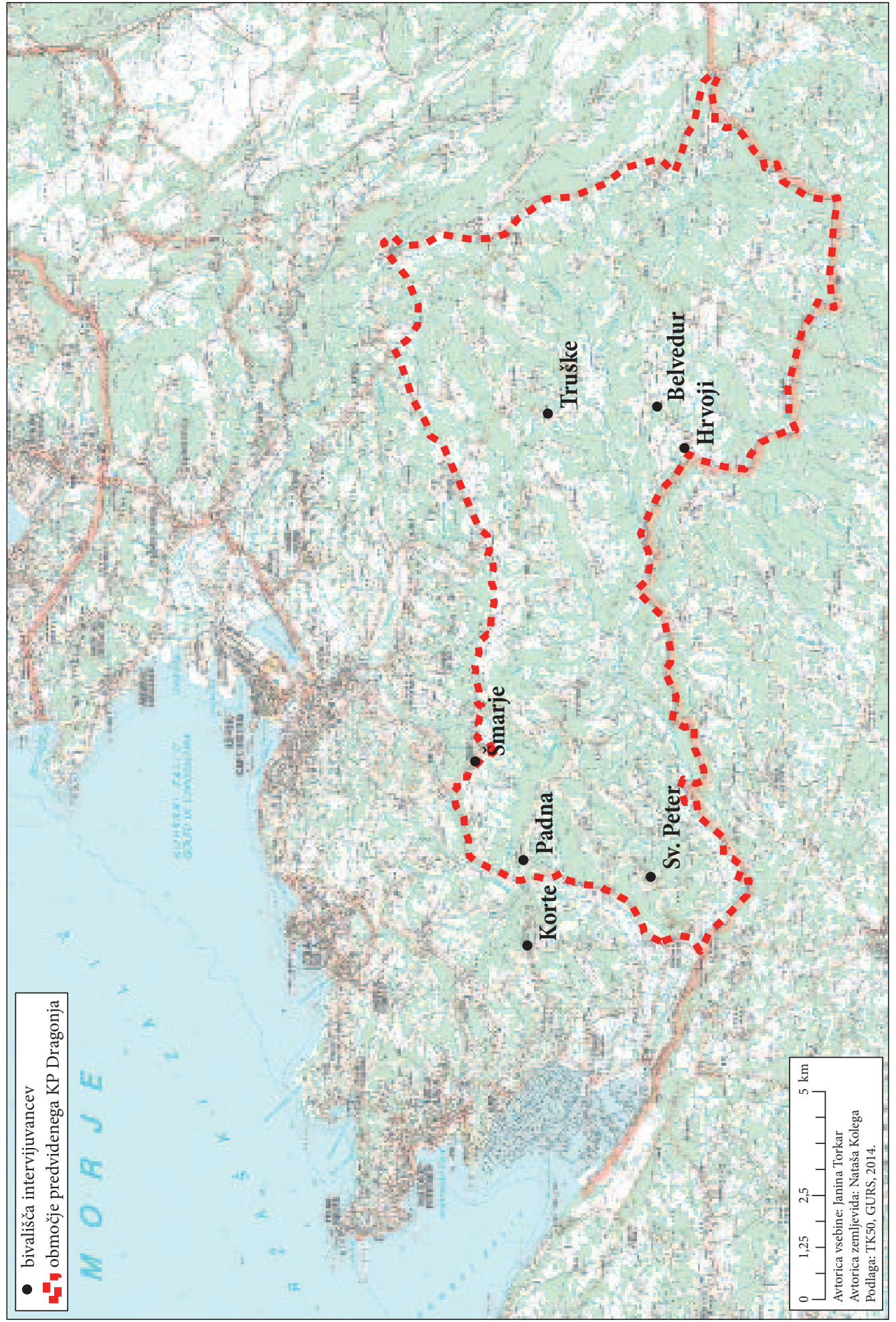


Marezige, Koštabona. V teh naseljih je danes več mladih družin z otroki. Nekateri med njimi so se priselili zaradi nižjih cen nepremičnin ali pa so se vrnili in obnovili domove svojih staršev. Na primer v Laborju, Brezovici pri Gradinu in Borštu se je v zadnjem desetletju število prebivalcev povečalo za približno tretjino, povprečna starost se je znižala pod 40 let, indeks staranja pa je krepko pod 100 (Krušec 2016). V preteklosti so se šole soočale s pomanjkanjem učencev, danes pa odpirajo nove oddelke in vedno več je potreb po varstvu predšolskih otrok (na primer v Svetem Antonu, Gračišču). Naselja so s tem oživela, več je kulturnih in drugih prireditev ter več aktivnih v društvih in organizacijah. Poleg obnove domov se obnavlja prometna in komunalna infrastruktura, urejajo javna zemljišča ter obnavljajo ali gradijo objekte za vaške in kulturne domove. Večina mlajših prebivalcev v teh naseljih je zaposlenih izven naselja bivanja, zato se obdelanost zemljišč ni povečala; nekatera naselja vedno bolj postajajo spalna naselja. V času izvajanja raziskave smo se s sogovorniki lažje srečali v Kopru ali Piranu kot na njihovih domovih. Velika gozdnatost in zaraščanje že zmanjšujeta raznolikost življenjskih okolij rastlin ter živali in privlačnost okolja za človeka, zaradi dnevne rekreacije, pohodništva ter kolesarjenja pa se ponovno čistijo in vzdržujejo vsaj nekdanje poti.

\section{Rezultati in razprava}

\subsection{Motivacija za sodelovanje v razvoju}

Kaj motivira prebivalce podeželja, da sodelujejo in se aktivno vključujejo v dogajanje v lokalnem okolju, je pomembno vprašanje. Naši sogovorniki, sicer aktivni posamezniki, so povedali: »Pomembna je spodbuda s strani posameznikov ali manjše skupine "zagnanih", njim se potem pridružijo nekateri sovaščani, toda večina se jih redko ali nikoli.« Poudarili so potrebo po dogovarjanju in informiranju o namenu, izvajanju ter rezultatih aktivnosti. Zlasti rezultati prebivalce spodbudijo k bolj aktivni udeležbi pri dejavnostih v domačem kraju. »Ko vidijo, da se nekaj naredi in izboljša, pridejo tudi tisti nezainteresirani«, nam je povedal sogovornik.

Nekateri sogovorniki so kot primer omenili akcijo »Očistimo Dragonjo 2015«, ki je bila organizirana meseca maja v sklopu širše aktivnosti Let's do Mediterranean in bili kritični do slabega odziva s strani lokalnega prebivalstva. Povedali so, da so v preteklosti prebivalci s skupnim delom na tako imenovanih komunih ali rabutah veliko postorili za skupno dobro, vključno $\mathrm{z}$ upravljanjem naravnih virov. $\mathrm{Z}$ odseljevanjem in spremembami, ki jih je najprej prinesla nacionalizacija, pa je skupno upravljanje naravnih virov, ki je bilo prej v domeni vaške skupnosti, počasi usahnilo. Tovrstne aktivnosti in večji del obveznosti je prešlo pod okrilje javnih ustanov in prebivalci so izgubili občutek odgovornosti ter potrebe po lastnem angažiranju. "Ljudje si želijo sprememb, ampak ne vedo, kako se lotiti, nimajo poguma«, nam je povedal eden od sogovornikov. Ob pregledu glasil in spletnih strani krajevnih skupnosti, kjer večino pozornosti namenijo prav poročilom o dogodkih v naseljih, smo opazili, da se vaške skupnosti trudijo oživljati vaški utrip in povezovati domačine v skupnih akcijah. Finančna sredstva, ki jih vaške skupnosti dobijo od krajevnih skupnosti, so večinoma porabljena za urejanje okolice naselij, vaških poti in objektov, porabijo jih za materialna sredstva, delo pa opravijo domačini. Število društev na podeželju slovenske Istre in tudi znotraj predvidenega KP Dragonja se je z leti precej povečalo. Sedaj ima mnogo vasi vsaj eno, če ne celo več društev. Turistična, kulturna, športna in društva za ohranjanje dediščine so, poleg prostovoljnih gasilskih in upokojenskih društev, najbolj zastopana. Društva skrbijo za organizacijo prireditev, kot so vsakoletni vaški prazniki ali šagre (na primer v Krkavčah, Sečovljah, Gračišču), proslave zgodovinskih dogodkov, predvsem iz druge svetovne vojne (na primer v Šmarjah, Loparju, Pobegih), pustovanja v večini vasi, kulinarični prazniki špargljev, blitve, česna (na primer v Padni, Novi vasi, Pomjanu, Gračišču) in pokušine vin (na primer v Marezigah).

Pred leti društva in aktivnosti po vaseh niso bile povezane in usklajene ter so imele večinoma lokalni pomen. Sedaj pa delujejo bolj usklajeno, da se dogodki časovno ne pokrivajo in vsebinsko podvajajo. 
Naši sogovorniki so povedali, da se trudijo ponuditi kaj izvirnega, novega, da se radi predstavijo na prireditvah v Kopru in želijo pritegniti obiskovalce iz širšega območja Istre. »Če imaš dobro idejo, dobiš tudi sponzorje, lahko se prijaviš na razpise in pridobiš finančna sredstva", so nam še povedali. Zavest o priložnostih, ki jih prinaša mreženje in to predvsem v luči (novih) politik razvoja podeželja, je bila ključna pri vzpostavitvi »Mreže za preporod Istre«. Mreža, ustanovljena marca 2015, združuje 13 nevladnih organizacij, ki delujejo na podeželju in se prek te tudi aktivno povezujejo in angažirajo, na primer Očistimo Dragonjo 2015, Istra brez gensko spremenjenih organizmov. Potočnik Slavičeva (2009) je z raziskavo dokazala, da obstajajo razlike v ravni prisotnosti socialnega kapitala na slovenskem podeželju. Razlike so večinoma posledica specifičnih okoliščin in vključujejo tudi motiviranost ter pripravljenost vaščanov do sodelovanja in angažiranja. V predhodnem poglavju smo omenili neugodno starostno sestavo in demografske trende, kar zmanjšuje vrednost socialnemu kapitalu na predvidenem območju KP Dragonja. Pozitivno pa ocenjujemo zavest prebivalcev o pripadnosti lokalni skupnosti, ki jo je moč ugotoviti iz sodelovanja $\mathrm{v}$ društvih in pri izvedbi aktivnosti ter prizadevanju aktivnih posameznikov za motiviranje in povezovanje sodelujočih. Angažiranje širše populacije v razvoj skupnosti je večplastni izziv. Že Lukšič (1998) je ugotovil, da je treba za doseganje večjega potenciala zainteresirano javnost pritegniti s profesionalnim angažiranjem. Tudi naši sogovorniki so poudarili, da bo za želene spremembe na bolje potrebna večja povezanost, potrebovali pa bi tudi pomoč.

\subsection{Seznanjenost $\mathrm{z}$ razvojnimi projekti}

Kljub temu, da so sogovorniki menili, da je informiranje širše skupnosti o razvojnih priložnostih pomanjkljivo, smo opazili, da so sami dobro seznanjeni z razvojnimi projekti in možnostmi za pridobivanje sredstev. Ponovno moramo omeniti, da so sogovorniki aktivni člani skupnosti in smo jih izbrali prav s tem razlogom. Večinoma so bili ali so še povezani s projekti zaradi svoje zaposlitve, vloge v lokalni skupnosti ali kot zasebniki, ki so finančna sredstva pridobili za zagon dejavnosti oziroma kot pomoč pri razvoju le-te. Vsi so menili, da je edina prava smer razvoja v slovenski Istri trajnostno naravnan razvoj dejavnosti. Te naj bi območju prinesle dodano vrednost in hkrati izboljšale življenje lokalnega prebivalstva. Da se zadovoljstvo prebivalcev ne meri zgolj z materialnim blagostanjem posameznikov, temveč tudi z uspešnim razvojem kraja, urejenostjo infrastrukture, izobraževanja in zdravstvene oskrbe ter z možnostjo kakovostne izrabe prostega časa, so ugotovili tudi Nicolao in sodelavci (2009). $\mathrm{Na}$ podlagi analize podatkov, pridobljenih na MOK in povzetih v preglednici 3, smo spoznali, da so bili že izvedeni projekti na območju predvidenega KP Dragonja namenjeni predvsem obnovi in izboljšanju infrastrukture, obnovi vaških jeder in posameznih objektov. Največ finančnih sredstev je bilo vloženih $\mathrm{v}$ osnovno infrastrukturo, kot so cestne povezave, vodovod in kanalizacija, pokopališča. Znotraj območja predvidenega KP Dragonja je v začetni fazi izgradnja vodovoda za Abitante, ki še nimajo pitne vode iz Rižanskega vodovodnega sistema. Odvajanje in čiščenje odpadnih voda ni v celoti urejeno v nobenem naselju. Manj sredstev je bilo namenjenim kulturnim in podobnim objektom, obnovam ter restavratorskim delom na sakralnih in drugih objektih kulturne dediščine, obnovi igrišč in podobno. Sogovorniki so povedali, da imajo izkušnje z zahtevno pripravo dokumentacije ob prijavi projektov, izpostavili so jih kot razvojno priložnost, tako za svoj kraj kot celotno istrsko podeželje. Menili so, da so dodatni napori pri pridobivanju sredstev iz razvojnih skladov upravičeni. Pozitivne učinke evropskih finančnih sredstev omenja Perez (2000), ki je ugotovil, da je program LEADER Španiji prinesel nov zagon, saj so ga lokalni odločevalci sprejeli kot pomembno politično orodje, s katerim so se lotili izbiranja ciljnih investicij in uresničevanja razvojnih projektov. Ljudje so ga prepoznali kot močan dejavnik pospeševanja in promocije razvoja podeželja ter spodbujanja lokalne kolektivne vključenosti. Iniciativa LEADER pri generiranju idejnih projektov spodbuja inoviranje kot pristop k razvoju podeželja. Ustvarjanje in promocija socialnih mrež v družbenih odnosih igra ključno vlogo pri izvajanju inovativnega ekonomskega razvoja, saj združuje različna znanja, izkušnje in veščine akterjev, ki lahko pripomorejo $\mathrm{k}$ razvoju inovacij ter olajšajo in pospešijo prenos znanja (Dargan in Shucksmith 2008). 
Preglednica 2: Investicije v obdobju 2010-2016 v krajevnih skupnostih na širšem območju predvidenega KP Dragonja (Mestna ... 2017).

\begin{tabular}{|c|c|c|c|c|}
\hline $\begin{array}{l}\text { krajevna } \\
\text { skupnost }\end{array}$ & opis & $\begin{array}{l}\text { vrednost } \\
\text { v evrih }\end{array}$ & $\begin{array}{l}\text { pridobljena } \\
\text { sredstva prek } \\
\text { razvojnih skladov }\end{array}$ & nosilec \\
\hline KS Šmarje & $\begin{array}{l}\text { I. faza gradnje kanalizacije, rekonstrukcija } \\
\text { nekaterih lokalnih cest v Šmarjah }\end{array}$ & 1.437 .302 & 661.402 & MO Koper \\
\hline KS Gradin & $\begin{array}{l}\text { obnova in nadgradnja doma v Brezovici, } \\
\text { etapna rekonstrukcija ceste Hrvoji-Krožič, } \\
\text { I. faza gradnje vodovoda Gradin-Abitanti, } \\
\text { obnova trga v Topolovcu, sanacijska dela } \\
\text { na zvoniku v Hrvojih }\end{array}$ & 549.599 & 120.64 & MO Koper \\
\hline KS Šmarje & $\begin{array}{l}\text { rekonstrukcija trga v vaškem jedru Šmarja, } \\
\text { rekonstrukcija nekaterih lokalnih cest, } \\
\text { obnova trga in rekonstrukcija objekta } \\
\text { pod spomenikom }\end{array}$ & 345.675 & 204.351 & MO Koper \\
\hline KS Šmarje & širitev pokopališča v Gažonu & 183.974 & 1 & MO Koper \\
\hline KS Marezige & $\begin{array}{l}\text { etapna rekonstrukcija ceste Babiči-Boršt, } \\
\text { gradnja zunanjega in notranjega odra } \\
\text { v zadružnem domu v Borštu, sanacija } \\
\text { lokalnih cest }\end{array}$ & 96.093 & 1 & \\
\hline KS Marezige & $\begin{array}{l}\text { obnova in širitev igrišča ob stari šoli } \\
\text { v Truškah }\end{array}$ & 84.747 & 1 & MO Koper \\
\hline KS Gračišče & prenova vežice na pokopališču & 71.041 & 1 & MO Koper \\
\hline KS Gračišče & $\begin{array}{l}\text { obnova, sanacija in restavratorska } \\
\text { dela v cerkvici in ureditev okolice } \\
\text { na pokopališču v Kubedu }\end{array}$ & 66.227 & 1 & MO Koper \\
\hline
\end{tabular}

Primerjava zgornjih podatkov $\mathrm{z}$ investicijami v drugih KS podeželja slovenske Istre je pokazala, da je bilo največ sredstev vloženih v izgradnjo kanalizacijskega sistema v Škofijah in Dekanih ter v prvo fazo obnove slemenske ceste v Hrvatinih. Precej finančnih sredstev je bilo porabljenih tudi za nadomestno stavbo osnovne šole v Svetem Antonu, zgrajen je bil nov vrtec v Pobegih, dodatne učilnice v Marezigah, Škofijah, Šmarjah in Hrvatinih. Na celotnem območju podeželja MO Koper je bilo več sredstev vloženih v infrastrukturne projekte $v$ krajevnih skupnostih $\mathrm{z}$ več prebivalci, ki so bližje obali ali so območja intenzivnejših suburbanizacijskih procesov (Mestna ... 2017). Večji projekti Občine Piran so bili izvedeni skupaj s sosednjima občinama Izolo in Koper. S projektom »Revitas « so opremili degustacijski center v Padni (30.541,63 evrov), s »Parenzano II « (28.800,00 evrov) so uredili počivališča za pohodnike in kolesarje ter postavili označevalne in informacijske table. S projektom »Parenzana Magic« je Občina Piran dopolnila infrastrukturo na "Poti zdravja in prijateljstva" na svojem območju. Uredili so tri počivališča za kolesarje, postavili orodja za športno vadbo v naravi ter informacijske table (80.400,00 evrov). S projektom »Revitas II (72.500,00 evrov) so uredili tri pohodne in tematske poti na območju vasi Padna, Nova vas in Sveti Peter ter obnovili kal. Organizirali so sejem tradicionalnih obrti Istre ter v sodelovanju $\mathrm{z}$ mestom Buzet sejem s sorodno vsebino na hrvaški strani. S projektom "HERA« (568.524,00 evrov) so organizirali konferenco o rabi kulturne dediščine v turistične namene, izdelali promocijsko multimedijsko gradivo in prenovili kulturni dom Božidarja Jakca v Padni. Projekt 
»Wellness Istra« (145.101,23 evrov) je podprl dogodek»Od vinarja do oljkarja«, ureditev spletne strani in obisk turističnega sejma v Avstriji (Občina Piran 2017).

\section{3 Želje in pričakovanja glede razvoja v lokalnem okolju}

Naši sogovorniki so bili pri presoji razvojnih možnosti precej enotni. Razvoj podeželja slovenske Istre in območja predvidenega KP Dragonja vidijo v turizmu in ekološki pridelavi hrane. To so izpostavili kot najpomembnejši razlog za varovanje narave, saj je za obe dejavnosti temeljnega pomena prav ohranjeno naravno okolje. Polovica sogovornikov je kot glavni »turistični produkt « omenila avtentičnost doživetja neokrnjene narave, biotsko raznovrstnost porečja Dragonje in prijaznosti lokalnega prebivalstva. Na podlagi analize dokumentov smo ugotovili, da je danes več aktivnosti usmerjenih v razvoj turizma kakor v razvoj kmetijstva. To kažejo že omenjene številne prireditve, urejenih in označenih je bilo mnogo tematskih (na primer vinske ceste, poti po vodnih virih), pohodniških in kolesarskih poti, med drugim tudi v okviru projekta LAS Istra. Poti so predstavljene na spletni strani MOK, nekatere tudi s tiskanimi gradivi v več jezikih, kaže namen, da informacija o njih doseže slovenske in tuje obiskovalce. Iz pregleda dokumentov je moč razbrati, da je v zadnjih letih nastalo tudi nekaj prenočitvenih zmogljivosti; zanimiv primer so »Hiške slovenske Istre«. Nekateri naši sogovorniki so izrazili mnenje, da bi bilo treba k razvoju turizma pristopiti skupaj in celovito, saj bi le tako privabili ter zadovoljili različne interese obiskovalcev. Goja (2015) opisuje pobudo glede razpršenega hotela, ki se odvija v vasi Padna. Ta predstavlja inovativen pristop organizacije turističnih nastanitev, ki jo dobro poznajo v Italiji in na Hrvaškem, razpršen hotel na podeželju slovenske Istre pa je novost. Že Nared (2005) je ugotovil, da je turizem pomemben motor $\mathrm{v}$ regionalnem razvoju, saj omogoča obstoj in nadaljnji razvoj številnih panog, ki sicer ne bi obstajale. $Z$ razvojem turizma lahko prebivalstvo najde delo v lokalnem okolju, se vključi v razvoj podeželja in s tem pripomore k ustvarjanju koristi za širšo okolico. Menimo, da bi s pomočjo starejših prebivalcev lahko obudili nekatere dejavnosti in prakse, kar bi prispevalo k ohranjanju žive kulturne dediščine ter obogatilo turistično ponudbo. Z obnovo obstoječih objektov bi poskrbeli za arhitekturno dediščino, mlajši prebivalci pa bi se morali aktivno vključiti in dopolniti ponudbo. Iz odgovorov smo razbrali, da sogovorniki cenijo tudi gastronomsko ponudbo, sestavljeno iz domačih sezonskih specialitet, kar bi lahko v prihodnje oživilo pridelavo in predelavo hrane. Ekološke kmetije, ki bi lahko aktivno prispevale $\mathrm{h}$ gastronomski ponudbi, na območju predvidenega KP Dragonja niso številne, pretežno pa so usmerjene v oljkarstvo in vinogradništvo. Ker območje ni primerno za intenzivno kmetijstvo, bi lahko rekli, da je večina pridelane hrane kakovostne, žal pa je pridelanega premalo, da bi preseglo potrebe pridelovalcev oziroma samooskrbo. Nekoč je bilo v slovenski Istri precej živinoreje, danes pa skoraj nič. Nekdanji pašniki so se spremenili v gozd, zaraščajo pa se tudi druga zemljišča. Reja drobnice, konj ali goveda bi bila zelo dobrodošla za ohranjanje kulturne pokrajine. Presenetilo nas je, da so sogovorniki pridelavo ekoloških pridelkov bolj povezovali s kakovostno turistično ponudbo kot s kakovostjo bivanja in z lastno oskrbo. Kot lahko sklepamo, je ekološka pridelava hrane zanje predvsem vir zaslužka, morda tudi zato, ker se sami lahko oskrbijo s pridelki poznanih pridelovalcev (sosedov, sorodnikov, prijateljev) brez certifikata ekološke pridelave ali jo pridelujejo sami. Bessiere (1998) je poudarjal, da sta lokalna hrana in gastronomija $\mathrm{z}$ vidika ohranjanja kulturne dediščine za podeželski turizem pomembni lokalni identiteti vsakega območja, ki združujeta lokalne proizvajalce, lokalno prebivalstvo in podeželski turizem. Kombinacija tradicije in inovativnosti obiskovalcem ponudi lokalne jedi kot avtentično gastronomsko izkušnjo.

Za razvoj dejavnosti, kot sta turizem in ekološka pridelava živil, je dostopnost proizvodov za potrošnike zelo pomembna in jo omogočajo dobre povezave med vasmi ter vasmi in urbanimi središči. Sogovorniki so menili, da je za razvoj najbolj zalednega dela slovenske Istre, to je Krajevne skupnosti Gradin, ki je ob meji s Hrvaško, cestna povezava z obalnim delom največja težava. Nekdaj jih je z dolino Dragonje povezovala utrjena pot, ki je danes uporabna le za pohodnike, sicer pa so naselja povezana z obalnimi mesti po veliko daljši cesti. Do Kopra potrebujejo 45 minut, do Pirana več kot uro. Javni 
avtobusni promet omogoča nekaj povezav dnevno in večina prebivalcev uporablja osebni avto. Domačin je izrazil upanje in dvom, da bo kdaj v prihodnosti obnovljena povezava z dolino Dragonje. „Če bo park, se to zagotovo ne bo zgodilo."Sogovorniki se zavedajo tudi obremenitev okolja z odpadnimi vodami, še zlasti, če bi razvijali turizem in bi se povečalo število prebivalcev. Poudarili so pričakovanja, da se neurejeno odvajanje odpadnih voda in divja odlagališča odpadkov čim prej uredijo, niso pa omenili, da bi v tej smeri lahko veliko naredili sami. Rastlinske ali druge biološke čistilne naprave so dobra možnost za čiščenje odpadnih voda v majhnih naseljih, veliko starih divjih odlagališč odpadkov je bilo odstranjenih v preteklih čistilnih akcijah, za nastajanje novih pa ni razlogov, saj je odvoz odpadkov urejen. Trije sogovorniki so omenili tudi potrebo po bolj urejenih kolesarskih in pohodniških poteh, saj se tudi označene poti zelo hitro zarastejo in postanejo neprehodne.

Predlog o zavarovanju območja bi vprašani podprli, vendar so ob tem izrazili negotovost, kako bi režim varovanja narave $v$ KP Dragonja vplival na prebivalce v vsakodnevnem življenju in gospodarjenju z lastnino. Strinjajo se, da je treba zavarovati identiteto Istre, istrskega človeka, kulturno in naravno dediščino ter druge naravne vrednote, hkrati pa si želijo upravljanje, ki bi dovoljevalo razvoj in vlaganja v gospodarske dejavnosti (turizem, kmetijstvo in obrt). Menijo, da bi prestrog režim varovanja zaviral razvoj infrastrukture in lokalnega gospodarstva, obnovo stavb, novogradnje in tako dalje. Priseljeni sogovornik je tudi poudaril, da neokrnjena narava in skrite zanimivosti »same po sebi« ne bodo pritegnile obiskovalcev, da je treba poskrbeti za interpretacijo naravnih vrednot, ponuditi aktivno preživljanje prostega časa na podeželju in primerno oskrbo. Meni, da brez dejavnosti, ki bi pritegnile obiskovalce kot posameznike, družine ali manjše skupine, jih zadržale na območju več dni in omogočile izvajanje v vseh letnih časih, ni smiselno graditi nastanitev. »Od dnevnih obiskovalcev imajo koristi samo gostilne, pa še to večinoma ob koncih tedna«, nam je še povedal.

\section{Sklep}

Aktivna udeležba prebivalcev pri izvajanju strategij razvoja lokalnih skupnosti ter pri varovanju narave in okolja je prepoznana kot nujna, učinkovita in demokratična. Novodobne politike razvoja podeželja to odobravajo kot pomemben dejavnik in z namenom, da bi prebivalce podeželja ustrezno aktivirali, tovrstne politike nudijo sredstva in možnosti za mreženje ter projektno sodelovanje. Vendar med tem, ko se nekateri aktivno udeležujejo in pozorno spremljajo aktivnosti, usmerjene k trajnostnemu razvoju podeželja slovenske Istre, je večina prebivalcev slabo seznanjena s tovrstnimi priložnostmi in dogajanjem ter redko sodeluje. Glede tega so sogovorniki mnenja, da je treba domačine več in redno obveščati, spodbujati in angažirati.

V zadnjih letih je sicer moč opaziti določene spremembe na bolje. Tudi prebivalci vasi na območju predvidenega KP Dragonja so se začeli povezovati in izoblikovale so se pobude za razvoj na njihovem območju, ki so usmerjene v trajnostne prakse v kmetijstvu in podjetništvu ter podpirajo varovanje okolja. Ugotovili smo, da se vsi sogovorniki dobro zavedajo kakovosti bivalnega okolja in velikega potenciala naravnih virov, kot so gozd, rodovitna prst, raznovrstnost naravnega okolja. Menijo, da je treba vse to ohraniti, hkrati pa razvijati dejavnosti, ki bodo z delovnimi mesti zadržale in pritegnile mlade prebivalce ter prispevale $\mathrm{k}$ še boljši kakovosti bivanja vseh. Možnosti vidijo v razvoju podjetništva oziroma socialnega podjetništva in v oživljanju obrti. Priliv informacij o dobrih praksah in inovativnih podjetniških idejah, ki uspešno delujejo drugje, je prispeval k oblikovanju mnenja, kako podeželje slovenske Istre umestiti v novodobne procese. Pred leti so tako le redki verjeli v razvoj turizma v notranjosti podeželja slovenske Istre, saj je bilo razširjeno mnenje, da se podeželje ne more kosati z razvito in uveljavljeno turistično ponudbo obalnih mest. Danes ni več tako. Domačini prepoznavajo priložnosti, povezane s trajnostnimi oblikami turizma, kjer obiskovalci želijo doživeti avtentičnost ter preživeti prosti čas v stiku $\mathrm{z}$ naravo in tradicijo. Sogovorniki so sicer mnenja, da bi bila v tem pogledu potrebna boljša "prepoznavnost območja in skupna blagovna znamka izdelkov«, s katero bi bilo mogoče doseči višjo dodano 
vrednost. Menijo, da je za uvrstitev območja na turistični zemljevid potrebna tudi zgodba, ki pritegne ter urejena turistična infrastruktura.

Zahvala: Predstavljena študija je del širše raziskave za magistrsko delo z naslovom »Presoja možnosti in pogojev soudeležbe prebivalcev v trajnostnem razvoju lokalne skupnosti«, ki jo je Janina Torkar zagovarjala na Univerzi na Primorskem. Stroške jezikovnega pregleda besedila so avtorice krile iz projekta st. 3044601, ki ga financira Östersjöstiftelsen (http://ostersjostiftelsen.se). Avtorice se zahvaljujejo g. Ferletiču z Mestne občine Koper in g. Goji za posredovane podatke ter ga. Klemenc za jezikovni pregled angleškega prevoda.

\section{Viri in literatura}

Arnstein, S. R. 1969: A ladder of citizen participation. Journal of the American Institute of Planners 35-4. DOI: https://doi.org/10.1080/01944366908977225

Barke, M., Newton, M. 1997: Spain, its regions and the EU »LEADER« initiative: some critical perspectives on its administration. Public Policy and Administration 12-3. DOI: https://doi.org/10.1177/ 095207679701200306

Bessiere, J. 1998: Local development and heritage: Traditional food and cuisine as tourist attraction in rural areas. Sociologia Ruralis 38-1. DOI: https://doi.org/10.1111/1467-9523.00061

Boström, M., Rabe, L., Rodela, R. 2015: Environmental non-governmental organizations and transnational collaboration: The Baltic Sea and Adriatic-Ionian Sea regions. Environmental Politics 24-5. DOI: https://doi.org/10.1080/09644016.2015.1027057

Brondizio, E. S., Ostrom, E., Young, O. R. 2009: Connectivity and the governance of multilevel socialecological systems: The role of social capital. Annual Review of Environment and Resources 34 . DOI: https://doi.org/10.1146/annurev.environ.020708.100707

Dargan, L., Shucksmith, M. 2008: LEADER and innovation. Sociologia Ruralis 48-3. DOI: https://doi.org/ 10.1111/j.1467-9523.2008.00463.X

Denzin, N. K. 2010: Moments, mixed methods and paradigm dialogs. Qualitative Inquiry 16-6. DOI: https://doi.org/10.1177/1077800410364608

Denzin, N. K., Lincoln, Y. S. 2000: Handbook of Qualitative Research. London.

Evropski kmetijski sklad za razvoj podeželja. Program razvoja podeželja, 2013. Medmrežje: http://www.program-podezelja.si/sl/prp-2007-2013/razvojne-osi/4-os-leader (12.5.2016).

Goja, D. 2015: Razvoj vasi Padna in vizija razpršenega hotela. Soustvarjamo trajnostni razvoj območja porečja Dragonje in podeželja Slovenske Istre. Koper.

Guštin, Š., Potočnik Slavič, I. 2015: Prepoznavanje in prostorska razmestitev konfliktov na podeželju. Geografski vestnik 87-1. DOI: https://doi.org/10.3986/GV87105

Hazler, V., Koščak, M., Makarovič, M., Pelc, S., Zajc, M., Kokolj-Prošek, J., Kokalj, V. 1999: Navodila za izvedbo programa uvajanja CRPOV in izdelavo razvojnega projekta CRPOV. Ministrstvo za kmetijstvo, gozdarstvo in prehrano. Ljubljana.

High, C., Nemes, G. 2007: Social learning in LEADER: Exogenous, endogenous and hybrid evaluation in rural development. Sociologia Ruralis 47-2. DOI: https://doi.org/10.1111/j.1467-9523.2007.00430.x

Jerman, K. 2011: Družbenogospodarski in prostorski vidiki oskrbe starejšega prebivalstva na koprskem podeželju. Diplomsko delo, Filozofska fakulteta Univerze v Ljubljani. Ljubljana.

Kladnik, D., Pipan, P., Gašperič, P. 2014: Poimenovanje Piranskega zaliva. Geografija Slovenija 27. Ljubljana.

Kokolj-Prosek, J., Golobič, B. 2002: Celostni razvoj podeželja in obnova vasi: CRPOV 1990-2002 - primeri dobrih praks. Ministrstvo za kmetijstvo, gozdarstvo in prehrano. Ljubljana.

Kovách, I. 2000: LEADER, A new social order, and the Central and East-European countries. Sociologia Ruralis 40-2. DOI: https://doi.org/10.1111/1467-9523.00140 
Krušec, K. 2016: (Sub)urbanizacijski procesi v mestni občini Koper s poudarkom na demografskih gibanjih v obdobju 2005-2015. Zaključno delo, Fakulteta za humanistične študije Univerze na Primorskem. Koper.

Lukšič, J. 1998: Okoljske nevladne organizacije v Sloveniji. Teorija in praksa 35-5.

Mannigel, E. 2008: Integrating parks and people: How does participation work in protected area management? Society and Natural Resources 21-6. DOI: https://doi.org/10.1080/08941920701618039

Mestna občina Koper. Interno gradivo o investicijah na podeželju. Koper, 2017.

Milestad, R., Bartel-Kratochvil, R., Leitner, H., Axmann, P. 2010: Being close: The quality of social relationships in a local organic cereal and bread network in Lower Austria. Journal of Rural Studies 26-3. DOI: https://doi.org/10.1016/j.jrurstud.2010.01.004

Moseley, M. J. 2003: Rural Development: Principles and Practice. London.

Mreža za preporod Istre. Medmrežje: http://preporodistre.weebly.com/ (12.5.2016).

Nared, J. 2005: Spodbujanje turizma in instrument trajnostnega regionalnega razvoja. IB revija 39-4.

Občina Piran. Interno gradivo o investicijah na podeželju. Piran, 2017.

Ostrom, E. 1990: Governing the Commons: The Evolution of Institutions for Collective Action. Cambridge, MA.

Ostrom, E. 2000: Collective action and the evolution of social norms. The Journal of Economic Perspectives 14-3. DOI: https://doi.org/10.1257/jep.14.3.137.

Pelc, S. 2000: Projekt celostnega razvoja podeželja in obnove vasi. Ljubljana: geografija mesta. Ljubljana.

Perez, J. E. 2000: The LEADER programme and the rise of rural development in Spain. Sociologia Ruralis 40-2. DOI: https://doi.org/10.1111/1467-9523.00142

Plummer, R., Fitz Gibbon, J. 2006: People matter: The importance of social capital in the comanagement of natural resources. Natural Resources Forum 30-1. DOI: https://doi.org/10.1111/ j.1477-8947.2006.00157.x

Podreka, J., Rodela, R. 2013: Lokalne akcijske skupine in varovanje okolja: pregled vsebin projektov, ki prispevajo k drugi osi Programa razvoja podeželja. Geografski vestnik 85-2.

Potočnik Slavič, I. 2008: Endogeni potencijal podeželja. Doktorsko delo, Filozofska fakulteta Univerze v Ljubljani. Ljubljana.

Potočnik Slavič, I. 2009: Socilani kapital na slovenskem podeželju. Dela 31. DOI: https://doi.org/ 10.4312/dela.31.2.21-36

Potočnik Slavič, I. 2010: Neoendogenous in- and output of selected rural areas. Revija za geografijo 5-1.

Pretty, J. N. 2003: Social capital and the collective management of resources. Science 302-5652. DOI: https://doi.org/10.1126/science.1090847

Pretty, J. N., Smith, D. 2004: Social capital in biodiversity conservation and management. Conservation Biology 18-3. DOI: https://doi.org/10.1111/j.1523-1739.2004.00126.x

Rodela, R. 2006: Triglavski narodni park: Analiza izkušenj lokalnega prebivalstva. Ljubljana.

Rodela, R., Udovč, A., Boström, M. 2017: Developing environmental NGO power for domestic battles in a multilevel context: Lessons from a Slovenian case. Environmental Policy and Governance 27-3. DOI: https://doi.org/10.1002/eet.1735

Shucksmith, M. 2010: Disintegrated rural development? Neo-endogenous rural development, planning and place-shaping in diffused power contexts. Sociologia Ruralis 50-1. DOI: https://doi.org/ 10.1111/j.1467-9523.2009.00497.X

The LEADER Approach: A Basic Guide. Luksemburg, 2006. Medmrežje: https://ec.europa.eu/ agriculture/sites/agriculture/files/publi/fact/leader/2006_en.pdf (12.5.2016).

Torkar, J. 2015: Presoja možnosti in pogojev soudeležbe prebivalcev v trajnostnem razvoju lokalne skupnosti - študija primera. Magistrsko delo, Fakulteta za Management Univerze na Primorskem. Koper.

Trampuš, T. 2009: Strokovni predlog za zavarovanje Krajinskega parka Dragonja. Medmrežje: http://www.zrsvn.si/dokumenti/63/2/2012/SP_pKPD_ZRSVN_feb09_2673.pdf (13.8.2016). 
Vogrinc, J. 2008: Pomen triangulacije za zagotavljanje kakovosti znanstvenih spoznanj kvalitativnega raziskovanja. Sodobna pedagogika 59-5.

Zorn, M. 2008: Erosion processes in Slovene Istria. Part 1, Soil erosion. Acta geographica Slovenica 49-1. DOI: https://doi.org/10.3986/AGS49102

\section{Summary: Rural development in the prospective Dragonja Landscape Park: a viewpoint from active inhabitants}

(translated by Romina Rodela)

The paper presents summarised results of a study that was aimed at investigating the opportunities for sustainable development of the rural area located within the boundaries of a prospective protected area, the Dragonja Landscape Park, in southwest Slovenia. In the past this area suffered out-migration and it is still sparsely populated today. Outmigration resulted in land abandonment and forest regrowth. We have recently observed that the younger inhabitants, of whom many are newly settled, started to be engaged in initiatives meant to improve local well-being and living conditions. Active inhabitants are a paramount resource for rural development: those active in community affairs have an important role in spreading out information to other residents, they contribute to maintaining relationships in the community and build social capital. We sought to study the way active inhabitants engage in community affairs and how they perceive challenges for rural development. This was approached by means of multiple methods. We first made a document analysis in which we collected information about activities that took place within this rural area (Istria). We reviewed websites and accessed reports and related materials that were made available on-line by local communities and associations. After that we undertook a non-obtrusive observation of participants in the workshop entitled "Creating Sustainable Rural Development of Istria « which sought to promote active involvement of the locals in the planning and management of local development. We observed how the participants interacted with one another, took notes of the topics discussed and of the concerns raised by the speakers and the participants. As a third step we also carried out semi-structured interviews with ten local inhabitants who are actively engaged in activities, are members of local organizations and/or are employed in the area this research is focused on. We collected information about the awareness of, and interest in, active participation in the activities meant to promote sustainable development of this area, about the valuing of natural resources, and information about the local needs and expectations regarding quality of life. We have found out that our respondents are well aware of local affairs, most of them have worked together and have had a positive experience with development projects.

Active locals are the driving force of rural development in Slovenian Istria, while developmental and similar projects are their main tool. Collaboration between professionals and the general public does not only bring about material assets, but also increases awareness, fosters broader education and strengthens local identity. Efforts to secure and use European and other funds for rural development have proved successful. As a result, buildings and cultural monuments have been refurbished, transport infrastructure, village markets, and other cultural heritage have been improved or maintained. Tourist infrastructure has also been partially set in place, including accommodation facilities, thematic, hiking and cycling trails, information boards etc. However, there are still lots of untapped potentials. In order to boost the leisure sector, tourist offer should be extended to other services, which, in addition to accommodation facilities, could include a range of soft and educational activities.

The study has ascertained that respondents link rural development with sustainable forms of economic engagement, such as ecotourism, organic farming, and the like. They see scope in small enterprises, social entrepreneurship, crafts and all the rest of what is necessary to meet the needs of local inhabitants, but also the processing of agricultural products and manufacturing of products from local materials. Respondents support the preservation of local and traditional knowledge. They see scope in the 
development of gastronomic offer that makes use of local produce (olive growing, viticulture, cultivation of vegetables and fruit, harvesting fruits and herbs, hunting). The study has shown that the development of social capital falls behind other aspects and this is a major obstacle to sustainable rural development of Slovenian Istria. Social capital is an important aspect in rural development. The study highlights the importance of (self)awareness and commitment to participation in community affairs. Respondents have identified a need for a better-organized inflow of information, the heightening of awareness, and exchange of knowledge, which could be achieved through a variety of events, workshops, presentations. With the analysis of documents and online material we have found out that lots of events are organized in the areas with active local associations (tourist, cultural and other). These associations collaborate and network widely and are well embedded in local affairs, which suggests that larger networks and/or communities are mobilised in different ways. This is, we believe, a positive prospect for the development of rural Istria. 